\section{PALABRAS CLAVE}

Condiciones económicas

Política económica

Empleo

Mercado de trabajo

Salarios

Zonas rurales

Zonas urbanas

Pequeñas empresas

Empresas medianas

Perú

\title{
Auge y heterogeneidad productiva. Perú 2002-2006
}

\author{
Norberto E. Garcia
}

$\mathrm{U}$

na parte de la población de Perú no percibió el auge económico en 2002-2006, entre otras razones, por la profunda heterogeneidad productiva de la economía peruana. En el 2006, un 53,4\% del empleo se hallaba en microempresas e independientes con trabajadores no remunerados, cuya productividad e ingreso laboral medio eran muy bajos. Entre el 2002 y el 2006, dicho ingreso creció muy lentamente, por lo que la mejora en el bienestar de ese segmento fue muy débil a pesar del auge experimentado. Hacia el futuro, parece indispensable desarrollar políticas orientadas hacia las microempresas con potencial competitivo, para lograr rápidos aumentos de su productividad que mejoren el bienestar de los allí ocupados. Asimismo, será preciso introducir en la política económica la idea de que ella tiene impactos diferenciados por segmentos, para que las medidas adoptadas incidan selectivamente en el segmento de microempresas, mejorando su competitividad. 


\section{I}

\section{Introducción}

El presente trabajo explora una de las razones por las que el auge económico del Perú en el período 2002-2006 no ha sido percibido como tal por una fracción significativa de la población. Esa razón es la profunda heterogeneidad productiva de la economía peruana, a la que se asocia una muy marcada segmentación del mercado laboral. Esto explica por qué el rápido crecimiento y modernización de determinados segmentos de la economía no se difundió con la misma velocidad hacia los restantes segmentos.

A continuación, la sección II describe el contexto en que tuvo lugar el auge que se inició en el 2002.

\section{II Contexto}

Entre el 2002 y el 2006, Perú registró el auge económico más importante de su historia reciente, después del de 1950-1955 inducido por la guerra de Corea. A la rápida expansión en los mercados externos de la demanda de minerales y otros productos extractivos, se sumó el efecto del Acuerdo de promoción comercial andina y erradicación de la droga (ATPDEA) $)^{1}$ de los Estados Unidos, que al reducir barreras arancelarias estimuló la diversificación de exportaciones no tradicionales hacia dicho país. A ello se agregó la promoción de exportaciones no tradicionales hacia muchos otros países del mundo y una política macroeconómica que priorizó la estabilidad.

El rápido crecimiento de los ingresos por exportaciones tradicionales y no tradicionales alcanzó al 30\% anual (medido en dólares corrientes) en el período 2002-2006. Las exportaciones a precios constantes crecieron en ese período a un ritmo de $12 \%$ anual. El coeficiente de exportaciones como proporción del producto interno bruto (PIB) a precios corrientes se elevó desde $14 \%$ en el 2002 a $28 \%$ en el 2006. Todo esto se tradujo también en un fuerte aumento de los ingresos tributarios, lo que permitió expandir el gasto público y reducir el déficit fiscal a cifras muy bajas.

\footnotetext{
${ }^{1}$ Andean Trade Promotion and Drug Eradication Act, de los Estados Unidos.
}

La sección III examina el desigual crecimiento del empleo y de los ingresos laborales en los diferentes segmentos del mercado de trabajo, destacando la importancia del segmento de las microempresas para comprender cómo operó el mercado laboral del país. La sección IV pone de relieve la necesidad de formular políticas dirigidas a las microempresas con mayor potencial competitivo, analiza el dispositivo de políticas vigente y hace sugerencias para el futuro. La sección V contiene las principales conclusiones.
Como resultado, el crecimiento del PIB se aceleró desde 3,9\% en el 2003 hasta $6,4 \%$ en el 2005 y $8,0 \%$ en el 2006, y se espera que sea de 7,8\% en el 2007. En el mismo período la productividad total se recuperó y creció a un ritmo de entre $3 \%$ y 3,5\% anual, por primera vez desde un breve interregno en 1993-1996. La inversión bruta fija siguió con cierto rezago la aceleración del PIB, contribuyendo así a la creación de nuevos empleos. En particular, la tasa de crecimiento del empleo en establecimientos urbanos de 10 y más ocupados se elevó desde un 3,0\% anual en el 2003 hasta un 5,7\% en el 2005 y un $8,9 \%$ en el 2006.

Uno de los hechos que sorprenden del actual auge peruano es que la percepción de él por una parte de la población no parece ser similar a la de los economistas. En el período 2003-2006 una fracción significativa de la población no se sintió beneficiada por el éxito económico, a tal punto que en las elecciones presidenciales del 2006 un $47 \%$ votó por abandonar el modelo económico exitoso y volver a las viejas prácticas del populismo, el desarrollo del mercado interno y las nacionalizaciones.

Existe una variedad de factores que convergen para explicar este desajuste entre el éxito económico y la percepción del mismo en una fracción muy grande de la población. Entre esos factores se hallan el muy desigual acceso a oportunidades en el punto de partida; el tiempo que demora el crecimiento económico en hacer sentir sus 
efectos sobre el empleo y los ingresos, la concentración de las exportaciones en un número relativamente pequeño de empresas y el rezago en materia de inversión y tecnología en la vasta economía campesina de la sierra andina. El propósito de este trabajo es explorar solo uno de ellos: el alto grado de heterogeneidad productiva en el punto de partida y sus efectos en el aumento del empleo, de los ingresos y del bienestar de la población.

La economía peruana es una de las economías latinoamericanas con mayor heterogeneidad productiva. Esto es válido para casi todos sus mercados y actividades de producción. En una misma actividad, al lado de una gran empresa moderna dotada de tecnología de punta, gestión empresarial de frontera, personal muy calificado y con gran experiencia, y un mercado de exportación dinámico, existen numerosas microempresas o pequeñas empresas sumamente atrasadas, con tecnología rudimentaria, débil capacidad de gestión, personal no calificado y carente de experiencia, y precaria inserción en mercados locales.

La heterogeneidad genera la segmentación de los mercados de productos y factores. Los mercados seg- mentados no se ajustan como los mercados homogéneos, sino que se caracterizan por el distinto tipo y velocidad de ajuste de los diversos segmentos. Si el Banco Central de la Reserva reduce en medio punto su tasa de interés de referencia, se abarata el crédito a las empresas privadas organizadas y formales, y esto probablemente contribuirá a expandir su demanda de créditos. Pero la misma medida no produce igual efecto en las microempresas, que seguirán enfrentando el racionamiento y muy alto costo del crédito.

Lo antes expuesto es particularmente cierto para un mercado laboral segmentado como el de Perú, en el cual el dinamismo de los sectores modernos y sus correspondientes segmentos en el mercado laboral no se transmite automática y proporcionalmente a los segmentos menos estructurados del mercado de trabajo. La segmentación no implica que existan compartimentos estancos dentro del mercado laboral, sino obstáculos, carencias y barreras que mediatizan la incidencia que tienen los cambios registrados en ciertos segmentos sobre los restantes.

\section{III}

\section{El crecimiento del empleo y del ingreso laboral según el tamaño del establecimiento}

\section{Las tendencias en el período 2002-2006}

La primera columna del cuadro 1 sintetiza el crecimiento del empleo por segmentos del mercado laboral en 2002-2006. Como se desprende de dicho cuadro, el empleo creció muy poco en la empresa mediana (50 a 199 ocupados) y grande (200 y más ocupados); en cambio, aumentó a un ritmo de $6,4 \%$ anual en la pequeña empresa (10 a 49 ocupados) y en 5,0\% anual en la microempresa ( 2 a 9 ocupados), de acuerdo con la información de la Encuesta Nacional de Hogares (cuartos trimestres, 2002-2006). La Encuesta Nacional de Sueldos y Salarios aplicada a establecimientos de 10 y más ocupados arroja un resultado más optimista: el empleo agregado de la pequeña, mediana y gran empresa creció a una tasa de 5,3\% anual en el período 2002-2006, la que tendió a acelerarse hasta alcanzar un $5,7 \%$ en 2005 y un $8,9 \%$ en 2006. La tasa de desempleo abierto (nacional) descendió desde 6,0\% en el 2002 hasta $4,5 \%$ en el 2006.
¿Cómo es posible que con ritmos tan elevados de crecimiento del empleo en segmentos formales no se haya percibido una intensa mejora del bienestar de toda la población? La respuesta se encuentra en la segunda columna del cuadro 1.

Hacia el 2006, a pesar del muy elevado crecimiento del empleo formal, un 53,4\% del empleo correspondía a microempresas y un 16,2\% a empleo independiente no calificado, abarcando en total casi un $70 \%$ del empleo del país. Una fracción significativa de estas dos categorías suele formar parte de lo que muchos analistas llaman empleo informal. La Organización Internacional del Trabajo (OIT), por ejemplo, utiliza como criterio para medir el empleo informal urbano la suma de quienes trabajan en microempresas de hasta cinco ocupados, los independientes no calificados, los trabajadores familiares no remunerados y el servicio doméstico.

Complementando lo expuesto, se destaca que después de cinco años de rápido crecimiento, el empleo en la pequeña, mediana y gran empresa representó en el 2006 
CUADRO 1

Perú: empleo, por segmentos, 2002-2006a (Porcentajes)

\begin{tabular}{llc}
\hline & $\begin{array}{c}\text { Crecimiento } \\
\text { medio anual }\end{array}$ & $\begin{array}{c}\text { Composición } \\
\text { porcentual }\end{array}$ \\
\hline 1. Sector público & 3,4 & 7,5 \\
2. Mediana y gran empresa & 0,4 & 9,4 \\
$\quad$ (50 y más ocupados) & & \\
3. Pequeña empresa (10 a 49) & 6,4 & 7,8 \\
4. Microempresa (2 a 9) & 5,3 & 53,4 \\
- 6 a 9 ocupados & 10,4 & 15,7 \\
- 2 a 5 ocupados & 4,2 & 37,7 \\
5. Independientes calificados b & $-0,4$ & 0,9 \\
6. Independientes no calificados & 1,1 & 17,1 \\
$\quad$ Urbanos & 1,9 & 12,8 \\
Rurales & $-0,8$ & 4,3 \\
7. Servicio doméstico & 5,4 & 3,8 \\
8. Empleo total & 3,8 & 100 \\
9. Desempleados & $-2,1$ & 4,5 \\
10. Tasa de ocupación & - & 95,5 \\
11. Población económicamente & 3,4 & 100 \\
activa (PEA) total & & \\
\hline
\end{tabular}

Fuente: Instituto Nacional de Estadística e Informática, Encuesta Nacional de Hogares (cuarto trimestre del 2002 y el 2006. Elaboración del Programa de Estadísticas y Estudios Laborales (PEEL) del Ministerio de Trabajo y Promoción del Empleo.

a Las cifras relativas al 2006 son preliminares. Los trabajadores familiares no remunerados se registran en el estrato de empresa donde trabajaron. Los independientes calificados y no calificados excluyen familiares no remunerados. Los independientes con familiares no remunerados se incluyen en el segmento de microempresa o pequeña empresa, según el número de familiares.

b Los independientes calificados incluyen profesionales, técnicos y afines.

sólo un 17,2\% del empleo total. Por consiguiente, aunque hubo un significativo crecimiento del empleo de calidad en estos estratos, su contribución al incremento total del empleo fue relativamente baja y, por ende, también baja su contribución al bienestar agregado.

Cabe añadir que en el período 2002-2006 descendió la proporción de independientes no calificados - por el mayor crecimiento del empleo en los establecimientos de todos los estratos- desde $19,5 \%$ a $17,1 \%$ del empleo total, pero su magnitud estuvo lejos de compensar la tendencia predominante.

Un factor de importancia es el elevado crecimiento de la población económicamente activa (PEA), que promedió un 3,4\% anual entre el 2002 y el 2006. Esto hace que, para desplazar una proporción significativa de la PEA hacia ocupaciones de mayor productividad, el empleo en las actividades respectivas deba crecer muy rápidamente, lo que a su vez obliga a alcanzar un muy alto crecimiento de la inversión, el PIB y la productividad en dichas actividades. De igual modo, ese alto crecimiento de la PEA se traduce en una presión permanente hacia el autoempleo o el inicio de nuevas microempresas, expandiendo así el bolsón de baja productividad.

Esa dicotomía entre empleo en microempresas y empleo independiente no calificado, por un lado, y empleo en pequeña, mediana y gran empresa, por otro, tiene importancia cuando se observan las diferencias de ingreso laboral medio entre esos segmentos. El cuadro 2 presenta información sobre el ingreso laboral mensual en el 2006, por segmentos, utilizando dos fuentes: la Encuesta Nacional de Hogares, cuarto trimestre, y la Encuesta Nacional de Sueldos y Salarios a establecimientos de 10 y más ocupados. Como se desprende de dicho cuadro, el ingreso laboral medio mensual en la microempresa fue de aproximadamente 561 soles, equivalentes en el 2006 a unos 174 dólares. Similarmente, el ingreso laboral medio de los independientes no calificados fue en el 2006 incluso menor que el de los trabajadores en la microempresa. ${ }^{2}$ Conviene recordar que entre los independientes calificados se incluye no solo a profesionales y técnicos, sino también a trabajadores afines, por lo que los independientes con una calificación muy baja, que de hecho suelen ser informales - como puede serlo un fontanero-, incluyen a aquellos que carecen de calificación alguna; esto contribuye a explicar las tendencias en materia de ingresos de unos y otros. En el caso de un trabajador independiente no calificado rural, el ingreso laboral medio por mes registrado en 2006 fue de 240 soles, equivalente a 75 dólares. En cambio, como muestra el mismo cuadro, el ingreso laboral medio por mes en la pequeña, mediana y gran empresa duplicó, triplicó o cuadruplicó el registrado en la microempresa, según el tamaño del establecimiento y la fuente estadística.

Lo anterior se ve reforzado por otro hecho que se dio en el período 2002-2006. El ingreso laboral medio por mes creció levemente en la empresa mediana y grande. Creció significativamente en la pequeña, por el aumento de la proporción de empleados, y por el alza de sus sueldos a un ritmo de 7,8\% anual en términos reales. Y creció a un ritmo mucho menor en la microempresa: un 2,4\% anual en términos reales. Dado el muy bajo nivel inicial, esto significó un incremento de 77 soles corrientes en cuatro años, equivalentes a 23 dólares (o sea, seis dólares por año). El ingreso laboral mensual se

\footnotetext{
${ }^{2}$ Fuera de los eventuales errores muestrales, un factor decisivo que explica esta tendencia es que el crecimiento de la demanda de trabajo se orienta hacia trabajadores calificados, mientras se reduce la demanda de no calificados.
} 
Perú: ingreso laboral mensual, por segmentos, 2006 ${ }^{\text {b }}$

(Soles del 2006)

\begin{tabular}{|c|c|c|}
\hline & Encuesta Nacional de Hogares & $\begin{array}{l}\text { Encuesta Nacional de Sueldos y Salarios a } \\
\text { establecimientos con } 10 \text { o más ocupados }\end{array}$ \\
\hline 1. Gran empresa (200 y más) & 1603,5 & 2501,1 \\
\hline 2. Mediana empresa (50 a 199) & 1270,7 & 1940,2 \\
\hline 3. Pequeña empresa (10 a 49) & 792,4 & $2323,7^{c}$ \\
\hline 4. Microempresa (2 a 9) & 561,4 & \\
\hline 2 a 4 ocupados & 528,2 & \\
\hline 5 a 9 ocupados & 742,7 & \\
\hline 5. Independientes no calificados ${ }^{\mathrm{d}}$ & $38, .6$ & \\
\hline Urbanos & 437,8 & \\
\hline Rurales & 239,3 & \\
\hline 6. Independientes calificados & 973,5 & \\
\hline 7. Servicio doméstico & 523,3 & \\
\hline 8. Sector público & 1257,6 & \\
\hline
\end{tabular}

Fuente: Instituto Nacional de Estadística e Informática, Encuesta Nacional de Hogares, cuarto trimestre del 2006, y Encuesta de Sueldos y Salarios a establecimientos de 10 ocupados y más (junio del 2006). Elaboración del Programa de Estadística y Estudios Laborales del Ministerio del Trabajo y Promoción del Empleo (PEEL/MTPE).

a Las cifras son preliminares.

b El ingreso medio mensual excluye a los trabajadores no remunerados.

c El ingreso laboral medio de este estrato es elevado por la incidencia del mayor número de empleados en establecimientos de hasta 49 ocupados, sobre todo en el comercio y los servicios.

d Incluye el ingreso de profesionales, técnicos y afines.

redujo en el segmento de trabajadores independientes no calificados, en términos reales y nominales.

En parte la explicación se encuentra entonces en que una proporción mayoritaria del empleo en el país se halla en puestos de trabajo de muy escasa productividad, que no han registrado una mejora significativa en sus muy bajos ingresos durante el período de auge. El empleo en el segmento de mayores ingresos y productividad puede crecer rápidamente; sin embargo, dada su baja ponderación inicial hasta ahora ha tenido un efecto acotado sobre el bienestar total, lo que no impide que este pueda aumentar mucho en un plazo más largo.

La dicotomía entre microempresa y pequeña, mediana y gran empresa es también relevante por un segundo rasgo que caracteriza a la economía peruana: existe un alto porcentaje de empleo asalariado no registrado o sin contrato laboral legal, con un salario inferior al mínimo y sin acceso a las prestaciones laborales no salariales. Hacia el 2006, más de un 55\% de los asalariados del sector privado carecían de un contrato laboral legal (MTPE/ PEeL, 2007) y más de un $75 \%$ de los asalariados de la microempresa se hallaban en esa situación. Puesto que la proporción de asalariados sin contrato es mucho más alta en las microempresas, la persistencia de una ponderación elevada de estas últimas en el empleo generaría también una porción significativa de la diferencia de ingresos laborales entre los asalariados de la pequeña, mediana y gran empresa, y los de la microempresa.

\section{El problema en el ámbito rural}

El crecimiento del período 2002-2006 se inició en las regiones de la Costa del país, estimuladas por el aumento de las exportaciones. Solo posteriormente se dinamizó la economía de Lima Metropolitana. Sin embargo, no ocurrió lo mismo en la Sierra o en la Amazonia. Cabe recordar que la PEA rural representa todavía poco más de un tercio de la PEA total, y que una proporción muy alta de ella se encuentra en la Sierra, donde predomina el minifundio de muy baja productividad. Esta expresión de la "microempresa campesina" de la Sierra tiene aún menos acceso a recursos y enfrenta mayores obstáculos que sus pares urbanas y, por lo tanto, exhibe niveles de productividad bajísimos. Usualmente carece de infraestructura, acceso a mercados y acceso al crédito. El muy reducido tamaño de las explotaciones dificulta la introducción de innovaciones, excepto por la vía de asociaciones de pequeños productores. Las pautas sociales y culturales son un factor adicional.

El cuadro 3 presenta varios indicadores que sitúan la dimensión del problema. El ámbito rural retiene 
CUADRO 3

\section{Perú: indicadores laborales por ámbito geográfico, 2004 \\ (Porcentajes)}

\begin{tabular}{|c|c|c|c|c|c|}
\hline & Urbano & $\begin{array}{l}\text { Lima } \\
\text { Metro- } \\
\text { politana }\end{array}$ & $\begin{array}{l}\text { Resto } \\
\text { ámbito } \\
\text { urbano }\end{array}$ & Rural & Total \\
\hline 1. Tasa de desempleo & 7,6 & 8,5 & 7,0 & 1,0 & 5,4 \\
\hline 2. Empleo total & 65,5 & 27,0 & 38,5 & 34,5 & 100 \\
\hline 3. Trabajo asalariado & 49,9 & 56,6 & 45,1 & 20,7 & 39,7 \\
\hline 4. Independientes & 40,2 & 35,2 & 43,8 & 52,3 & 44,4 \\
\hline 5. Familiares no remunerados & 6,3 & 3,5 & 8,3 & 25,5 & 13,0 \\
\hline 6. Ingreso laboral ${ }^{\mathrm{a}}$ & 788 & 1062 & 597 & 233 & 594 \\
\hline
\end{tabular}

Fuente: Ministerio de Economía y Finanzas, sobre la base de la Encuesta Nacional de Hogares 2001-2004.

a En soles corrientes del año 2004.

todavía un 34,5\% del empleo total del país, porcentaje superior al de la PEA empleada en Lima, pero en las zonas rurales los trabajadores asalariados representan i) solo un 20,7\% del empleo total, en comparación con el $50 \%$ en áreas urbanas; ii) un 52\% de trabajadores independientes, en comparación con el $40 \%$ en áreas urbanas; iii) un $25,5 \%$ de trabajadores familiares no remunerados, frente al 6,3\% en áreas urbanas, y iv) un ingreso laboral medio equivalente a un $23 \%$ del registrado en Lima Metropolitana. Como lo que el cuadro muestra para el ámbito rural son promedios, la situación de la Sierra Rural es aún más difícil que la reflejada en ellos. Asimismo, el Ministerio de Economía y Finanzas (2006) ha estimado, basándose en datos de la Encuesta Nacional de Hogares 2001-2004, que un 80\% de las personas activas de la Sierra ganan menos que la mitad de la canasta básica de consumo, frente a cifras de $48 \%$ en la Costa y $41 \%$ en Lima Metropolitana. Todo lo expuesto apunta a un problema de muy baja productividad en el ámbito rural, particularmente en la Sierra.

En la actual administración se inició el programa Sierra Exportadora, cuyo objetivo es diversificar la oferta y alcanzar niveles de calidad y volúmenes competitivos. Para ello promueve numerosos proyectos, en los que una empresa privada inversionista se articula con un gran número de pequeños productores, les transfiere conocimientos e insumos y comercializa su producción. Este programa es sin duda un avance notable, pero cabe preguntarse si podrá provocar un cambio masivo en un escenario en el que predominan minifundios sin potencial competitivo. Es probable que a largo plazo se necesiten cambios en el mercado de tierras para ir estableciendo la superficie mínima requerida para adoptar innovaciones y elevar la productividad.

\section{IV}

\section{Las políticas hacia las microempresas}

La heterogeneidad está presente en casi todos los mercados internos con gran intensidad, porque un $97 \%$ de las empresas del país son microempresas, un 2,8\% empresas pequeñas y solo un $0,2 \%$ medianas y grandes (MTPE/ PEEL, 2007). Se manifiesta en marcadas diferencias de productividad e ingresos laborales según el tamaño del establecimiento.

Pero esto es solo una manifestación. Lo que realmente explica tales diferencias es el muy desigual acceso a recursos. Mientras la pequeña, mediana y gran empresa acceden al crédito, están gestionadas por personal muy calificado, trabajan con mano de obra capacitada, invierten en capital fijo, capital humano e innovaciones, poseen información y están bien insertadas en mercados internos y externos, lo opuesto sucede en la mayoría de las microempresas. Así, su acceso al crédito es restringido y muy caro. Solo $0,1 \%$ de las microempresas exporta. $\mathrm{Su}$ productividad y rentabilidad no les permite pagar por la capacitación laboral o de gestión; carecen de los recursos, el capital y la información necesarios para incorporar innovaciones e invertir, y su identificación e inserción en los mercados suele ser muy débil y estar vinculada a mercados locales, muchas veces en forma precaria.

Todo lo anterior se traduce también en una altísima tasa de mortalidad, muy superior a las de la mediana y la gran empresa. Un $80 \%$ de las microempresas cierra sus puertas antes de completar su tercer año (Matthews, 2007) y un $43 \%$ de las microempresas que exportan no supera los dos primeros años de vida (ADEX, varios años). Esto significa que la tasa de riesgo es bastante más elevada en el segmento de las microempresas, y así lo perciben los bancos comerciales.

La muy elevada tasa de mortalidad es más que compensada por una muy alta tasa de iniciación de nuevas microempresas. Dada la magnitud de las tasas de entrada 
y salida de estas empresas, tras la aparente estabilidad de los promedios estadísticos de las variables de acervo hay un significativo dinamismo de las variables de flujo. Por ese motivo las entradas y salidas de personal a este segmento son significativas.

Lo expuesto repercute directamente en el tipo de puestos de trabajo y nivel de ingresos laborales que las microempresas pueden generar: de escasa productividad, con bajos ingresos e inestables. Esto incide significativamente en el bienestar de la población, dada la alta proporción del empleo total que corresponde a las microempresas: un 53\% en 2006.

Aun suponiendo un crecimiento futuro muy alto del empleo en la pequeña, mediana y gran empresa (por ejemplo, de $8 \%$ anual sostenido, superior al 5,9\% anual registrado en el período 2002-2006) ${ }^{3}$, así como un crecimiento esperado de la PEA de $2,4 \%$ anual, ${ }^{4}$ llevaría catorce años duplicar la proporción del empleo en la pequeña, mediana y gran empresa, para pasar del 17,2\% registrado en el 2006 a un 34,9\% en el 2020. Si se usara como referencia la Encuesta Nacional de Hogares, cuartos trimestres, el argumento se fortalecería aún más. En ese escenario, la proporción del empleo correspondiente a las microempresas descendería un poco, pero la brecha de productividad e ingresos entre ese segmento y los demás continuaría ampliándose. Este simple ejemplo sugiere que, además de procurar un alto crecimiento del empleo en la pequeña, mediana y gran empresa, es indispensable formular y aplicar políticas productivas para acelerar el incremento de la productividad y la competitividad de la microempresa.

Además, parece muy poco probable que el auge experimentado por la economía peruana, muy sensible a la evolución de los mercados externos, se prolongue catorce años más, lo que hace más perentoria la necesidad de establecer políticas públicas en favor de la microempresa.

Pese a la gran importancia de las microempresas para el empleo del país, las políticas públicas y privadas de Perú dirigidas a este segmento son escasas, dispersas y débiles. Colombia, cuyo tamaño económico es 1,5 veces el de Perú, destina 12 veces más recursos a apoyar a las microempresas: unos 4.000 millones de dólares frente a 340 millones, respectivamente. De igual manera, en el 2006 la entidad responsable de los programas orientados a las microempresas —el Centro de Promoción de la

\footnotetext{
${ }^{3}$ Según la Encuesta Nacional de Sueldos y Salarios a establecimientos de 10 y más ocupados.

${ }^{4}$ Según División de Población (CELADE), 2007.
}

Pequeña y Microempresa, conocido como PROMPYME e integrado en 2007 al Ministerio de Trabajo y Promoción del Empleo con el nombre de Mi Empresa- contaba con un presupuesto anual de 1,9 millones de dólares, en comparación con los 350 millones que destinaba a programas similares el Servicio Brasileño de Apoyo a las Micro y Pequeñas Empresas (SEBRAE), o los 50 millones que dedicaba la Corporación de Fomento de la Producción (CORFO) en Chile para apoyar el desarrollo competitivo de las empresas de este tipo.

En este trabajo no se evaluará todas las políticas de servicios financieros y de desarrollo empresarial dirigidas a las microempresas y pequeñas empresas (MYPE) vigentes en Perú. Sólo se analizará: i) el grupo objetivo, ii) la actividad informal, iii) el acceso al crédito, iv) el acceso a la capacitación laboral y de gestión, v) el acceso a innovaciones, vi) las normas laborales, vii) la tributación y viii) las aglomeraciones productivas y la subcontratación.

\section{Grupo objetivo}

El segmento de la microempresa es sumamente heterogéneo, pues incluye tanto unidades con potencial competitivo como microempresas de sobrevivencia. Se estima que en el 2006 aproximadamente 700.000 microempresas de las 2.100 .000 existentes poseían potencial competitivo (García, 2007). Hacia ellas deberían orientarse las políticas de promoción y aumento de la competitividad si se desea evitar que las políticas a favor de este segmento se transformen en oxígeno temporal de carácter asistencial.

\section{Actividad informal}

Un tema crítico es el de la actividad informal ("informalidad"), en su acepción de evasión masiva de normas o economía sumergida. Aproximadamente 650.000 microempresas y pequeñas empresas se hallan registradas en la Superintendencia Nacional de Tributación (SUNAT), de un total superior a 2,3 millones, lo que implica que $70 \%$ de dichas empresas son "informales" para la autoridad tributaria. Algo similar se observa en los registros laborales, del seguro de salud y de las autoridades locales. Esto pone sobre el tapete un tema central: qué políticas pueden ser esenciales para "formalizar" una fracción importante de las empresas que están evadiendo todas las normativas en vigor. La respuesta es evidente: la microempresa solo se formalizará cuando las ventajas de hacerlo superen a las desventajas, lo que apunta a la necesidad de complementar las políticas vigentes con 
un conjunto bien concebido de medidas orientadas a las MYPE. En este artículo se propone un quid pro quo: dar acceso a todas las políticas que se sugieren en las secciones siguientes a aquellas microempresas que se "formalicen".

Un paso necesario es reducir el costo, tiempo y complejidad de los trámites requeridos para constituir o registrar una empresa. En esto se ha avanzado a nivel nacional, aun cuando se podrían simplificar aún más los trámites y su costo. A nivel local todavía existen obstáculos, a pesar de que diversas autoridades locales ya han acordado simplificar y reducir los plazos y costos de los trámites.

\section{Acceso al crédito}

En los mercados crediticios las MYPE enfrentan dos restricciones. La primera es de acceso: se les raciona el crédito, ya que la oferta crediticia para las MYPE es muy inferior a su demanda. La segunda restricción, vinculada a la primera, es la del costo del crédito. Para las MYPE el costo del crédito suele ser entre cinco y siete veces mayor que el pagado por la mediana y gran empresa. Según la Superintendencia de Banca, Seguros y AFP (SBS), a fines del 2006 las tasas de interés medias para créditos a microempresas se hallaban entre el $38 \%$ y el $53 \%$, según el tipo de crédito e institución financiera; estas cifras superaban varias veces el $8,2 \%$ para descuentos y préstamos comerciales que ofrecían los bancos en esa misma fecha a las empresas de mayor tamaño. Las consecuencias han sido el encarecimiento de los costos de producción de las MYPE, una reducción de su capacidad competitiva y mucho menores posibilidades de invertir en tecnología, equipos y capital humano.

Con ello, las MYPE se ven obligadas a inmovilizar una mayor proporción de su capital de trabajo en acervos de insumos, mercaderías o cuentas por cobrar. $\mathrm{Al}$ inmovilizar una proporción mayor de su capital en activos circulantes, disponen de mucho menos capital para adquirir activos fijos (equipos) o innovaciones, o invertir en capital humano. Por consiguiente, la restricción del acceso al crédito que afecta a las MYPE repercute directamente sobre los factores que les habrían permitido elevar su productividad.

A fines del 2006 el crédito financiero a las microempresas se apoyaba en un sistema integrado por 10 bancos comerciales, 13 cajas municipales (CMS), 12 cajas rurales de ahorro y crédito (CRAC) y 13 entidades de desarrollo de la pequeña y microempresa (EDPYMEs). De los 10 bancos comerciales que tenían actividades microfinancieras, tres concentraban el $80 \%$ de las co- locaciones: el Banco de Crédito, el Banco del Trabajo y Mi Banco.

De acuerdo con los registros de la SBS, el saldo de créditos directos de las instituciones microfinancieras llegó en diciembre del 2006 a los 4.935 millones de soles, de los cuales 2.678 millones fueron créditos directos a microempresas (636. 000 deudores). Esta cifra representaba un 3,5\% del total de créditos del sistema financiero al sector privado, lo que da una clara idea de la asimetría existente en el acceso al crédito en Perú.

Entre las sugerencias para ir mejorando la situación en materia de créditos, cabe mencionar: i) el uso de una nueva tecnología crediticia, ya experimentada en la agricultura por la Corporación Financiera de Desarrollo (COFIDE) ${ }^{5}$ para impulsar préstamos a grupos de microempresas; ii) el fortalecimiento del sistema de microfinanzas, y iii) el establecimiento de fondos de garantía y de riesgo para promover el crecimiento de las microempresas con potencial competitivo. La ampliación y actualización de los registros de MYPE es también una información necesaria y útil para las entidades que operan en microfinanzas.

\section{Acceso a capacitación laboral y de gestión}

La baja productividad de la microempresa no le permite gastar en capacitación laboral y de gestión de la misma manera que lo hacen las empresas de mayor tamaño. La información disponible señala que el gasto medio de la microempresa en capacitación laboral es un décimo del promedio nacional y un vigésimo del gasto en capacitación de la mediana y gran empresa (García, 2005). Mientras el $50 \%$ de las empresas medianas y grandes capacitan, de las pequeñas lo hace el $18 \%$ y de las microempresas solo el 9,1\% (Chacaltana, 2004). En lo que respecta a capacitación en gestión empresarial, únicamente un $26 \%$ de los microempresarios tiene instrucción secundaria completa, lo que hace más necesaria la capacitación en gestión para este segmento. Sin embargo, no más del $7 \%$ de las microempresas acceden a servicios de asesoría en este campo, los que en su mayoría apuntan a temas de contabilidad y tributación, y no a la gestión empresarial propiamente dicha. En la actualidad opera un sistema de costos compartidos con bonos (Bonopymes) que se entregan al microempresario: este recibe tres bonos para capacitación con descuentos de hasta 49 soles cada uno, y otro para servicios de asesoría con un descuento de $70 \%$ y límite de 600 soles. No obstante,

\footnotetext{
${ }^{5}$ La COFIDE es banca de segundo piso.
} 
el número total de bonos emitidos es de unos pocos miles, de modo que el monto máximo transferido es de 200.000 dólares anuales, en circunstancias que la demanda potencial provendría de 700.000 empresas y llegaría a millones de dólares. Además, la asesoría que ofrecen las empresas privadas que brindan servicios y operan en este ámbito no responde a la demanda efectiva de la microempresa, por ejemplo en temas de gestión y aumento de productividad.

Se sugiere entonces establecer un fondo para financiar la capacitación laboral y capacitación en gestión de las MYPE, y un incentivo en la forma de un crédito tributario con un tope anual de 1,5\% de la nómina salarial. Simultáneamente, es factible diseñar y financiar una capacitación breve para el personal de las empresas de asesoría que operan con las MYPE, concentrada en la comercialización y la gestión en materia de productividad y calidad para las microempresas.

\section{El acceso a innovaciones}

El aumento sostenido de la productividad depende de la capacidad de incorporar innovaciones de productos y procesos. Cuando se parte de niveles bastante bajos, con cambios relativamente simples en productos y procesos, se contribuye de manera significativa al aumento de la productividad. Un ejemplo reciente en Perú es la adopción de nuevas técnicas simples de cultivo y riego, que elevaron notablemente los rendimientos y la productividad en la incipiente agricultura de exportación. No obstante, para que haya incorporación de innovaciones debe haber incentivos, ${ }^{6}$ un mínimo de capacidad de detección de las tecnologías disponibles a nivel mundial y recursos para financiar esa incorporación. El segmento de microempresas carece de las tres cosas. Aunque se registra un esfuerzo del Estado, en la forma de centros de innovación tecnológica (CITE) patrocinados por el Ministerio de la Producción, en la práctica es difícil reemplazar cientos de miles de iniciativas privadas en este ámbito.

El sistema de bonos mencionado no cubre significativamente a la microempresa ni induce en ella un cambio hacia la innovación. La alternativa es establecer bonos de costo compartido que se apliquen a la adquisición de innovaciones y a asistencia técnica para incorporar la innovación. También pueden establecerse bonos

\footnotetext{
${ }^{6}$ La mayor rentabilidad derivada de adoptar una innovación tiende a disiparse a medida que otros competidores hacen lo mismo. Por consiguiente, es necesario un incentivo para igualar la rentabilidad privada con la rentabilidad social para masificar las innovaciones.
}

colectivos para conjuntos de microempresas, y combinar los bonos para innovar con los correspondientes a capacitación laboral y de gestión.

\section{Normas laborales}

En el 2005, el costo laboral medio (legal) por hora trabajada era de 2,60 dólares (García, 2007). Este costo se desagregaba en un costo salarial de 1,62 dólares la hora, que se hallaba entre los más bajos de América Latina, y en un costo laboral no salarial de $61 \%$, que se ubicaba entre los más elevados de la región. No obstante, este promedio es poco representativo de lo que realmente sucede a nivel de establecimiento. Así, en la gran empresa el costo laboral estándar por hora en el 2005 era de 4,95 dólares, en la mediana empresa de 3,23 dólares, en la pequeña de 2,81 dólares y en la microempresa de 1,29 dólares. Las diferencias son entonces notables. Además, si se toma en cuenta el costo laboral efectivamente pagado y no el estándar legal, las diferencias se hacen mayores, porque en la microempresa no se paga el salario mínimo ni se entregan las prestaciones que integran el costo laboral no salarial. En este caso, el costo laboral efectivo por hora en la microempresa se reduce a 0,80 dólares la hora.

Por consiguiente, un primer aspecto que emerge de lo expuesto es que en el grueso de las microempresas y para la mayoría de los ocupados del país, las prestaciones legales que integran el costo laboral no salarial (vacaciones, seguro de salud, pensiones, gratificaciones o aguinaldo, asignación familiar, aporte de compensación por tiempo de servicio para situación de desempleo, jornada legal semanal, indemnización por despido y participación legal en utilidades), son irrelevantes porque son evadidas. Lo mismo sucede con el salario mínimo legal. En el 2006, el salario mínimo legal ascendía a 500 soles mensuales. La Encuesta Nacional de Hogares del cuarto trimestre del 2006 señalaba que el $60 \%$ de los trabajadores de las microempresas tenía un ingreso laboral inferior al mínimo. Si a ello se agrega que muchos de los que percibían más que el mínimo lo lograban mediante jornadas de más de ocho horas y trabajo en días feriados, es fácil inferir que para una fracción muy grande de las microempresas el salario mínimo no se aplica y es evadido.

Cuando el $80 \%$ de los establecimientos cumple con las normas y el $20 \%$ no lo hace, se puede hablar de evasión y cabe preocuparse por mejorar los sistemas de fiscalización y control. Pero cuando solo una fracción del 3\% de los establecimientos que representan 17\% del empleo cumple con las normas laborales, y el grueso del 
97\% restante no lo hace, es imprescindible replantear el tema y preguntarse si el segmento de las microempresas tiene un nivel de productividad que le permita cumplir con las normas laborales vigentes. Es necesario entonces adaptar las normas a la realidad y no pretender lo contrario. Una vez más, la fuerte heterogeneidad productiva que caracteriza al país sugiere que no es factible aplicar al segmento de la microempresa las mismas normas laborales que a las empresas de mayor tamaño y mayor productividad. Tampoco es factible aplicar el mismo salario mínimo. Un salario mínimo único de 500 soles puede resultar muy alto para la productividad de muchas microempresas y muy bajo para la productividad de todas las empresas medianas y grandes.

De hecho, lo anterior ya fue reconocido en el 2003 al aprobarse la ley 28.015, que redujo apreciablemente el costo laboral no salarial para las microempresas. No obstante, entre el 2003 y fines del 2006 solo se registraron y formalizaron 16 mil microempresas bajo este nuevo régimen. $\mathrm{Si}$ admitimos que un alto porcentaje de las microempresas registradas sucumbió ya a la elevada mortalidad en su segmento, es probable que hoy haya unas 7.000 microempresas - de un total de 2,1 millones- que estén operando acogidas al nuevo régimen laboral de excepción. Esto indica que no es fácil inducir a las microempresas a registrarse en este nuevo régimen, sin poner en práctica un conjunto de medidas complementarias de acceso a recursos que las beneficien. Dicho de otra manera, para que un régimen laboral de excepción tenga los efectos buscados tiene que ir acompañado por medidas complementarias en otros ámbitos de política que permitan acceder a recursos y elevar la productividad. La razón es bien sencilla: la microempresa — como cualquier otra empresa — necesita rentabilidad, demanda de sus productos y acceso a recursos para elevar su productividad. La rentabilidad potencial puede ser provista por un régimen laboral de excepción y/o subsidios implícitos en otras políticas. Pero si no se mejora el acceso a recursos, seguirá siendo poco probable que haya aumento sostenido de la productividad y la producción en las microempresas dotadas de potencial competitivo, y por ende, de su rentabilidad efectiva. Las normas laborales especiales para este segmento serán adoptadas por un mayor número de microempresas si a la vez se formulan y aplican políticas complementarias que amplíen su acceso a recursos.

Lo expuesto conduce a un tema crucial. Como se sabe, el costo laboral relevante para fines de competitividad es el costo laboral por unidad producida, expresado en divisas, y no el costo laboral por hora. El costo laboral por unidad producida se define como la relación entre el costo laboral por hora y la productividad por hora, corregidos por el tipo de cambio para expresarlo en divisas. En esta perspectiva, la microempresa puede tener un costo laboral por hora bajo y seguir siendo mucho menos competitiva que la grande si su productividad es muy débil. Un ejemplo permite esclarecer este punto. Una empresa grande con un costo laboral de 5 dólares por hora y una productividad de 12 dólares por hora, tiene un costo laboral por unidad producida de 0,42 dólares por hora (5/12). Una microempresa con un costo laboral de 1,29 dólares por hora y una productividad de 2,1 dólares por hora, tiene un costo laboral por unidad producida de 0,61 dólares por hora $(1,29 / 2,1)$. Por consiguiente, si desea competir está obligada a evadir las normas laborales y reducir su costo laboral efectivo hasta 0,86 dólares la hora para, con una productividad de 2,1 dólares la hora, operar con un costo laboral por unidad producida de 0,41 dólares la hora, ligeramente inferior al de la empresa grande. ${ }^{7}$ En este ejemplo se ve con mucha claridad lo importante que es el acceso a recursos para elevar la productividad de la microempresa y hacerla más competitiva.

\section{Tributación}

Una de las razones que impidió que se registrara un número mucho mayor de microempresas en el régimen laboral especial creado en el 2003, fue el costo de la tributación que enfrentaban al registrarse. Si se rebaja de $61 \%$ a $30 \%$ el costo laboral no salarial, el costo laboral total de la microempresa se reducirá en aproximadamente $19 \%$. Suponiendo que los costos laborales totales representen un 35\% de los costos totales, el beneficio provisto por el régimen especial es equivalente a $0,19 \times 0,35$, esto es, a menos del 7\% de los costos totales iniciales. Pero, al registrarse, la microempresa debe comenzar a tributar. El impuesto general a las ventas es de $19 \%$. El impuesto a la renta, dependiendo del escalón de utilidades y el tamaño de la empresa, oscilará entre el $5 \%$ y el $14 \%$ de las utilidades, según el régimen especial que se aplique (RUS O RER $)^{8}$, que equivalen aproximadamente a entre el $1,7 \%$ y el $5 \%$ de las ventas. En suma, al registrarse una microempresa la tributación elevará el costo total de ella entre $21 \%$ y $24 \%$ y a cambio obtendrá un beneficio menor a 7\%. Aun corrigiendo los costos y beneficios previos por una probabilidad de detección de $33 \%$ (admitiendo

\footnotetext{
${ }^{7}$ El tipo de cambio nominal en el 2006 era de 3,15 soles por dólar, factor que puede ser usado para traducir el ejemplo a soles.

${ }^{8}$ RUS: régimen único simplificado; RER: régimen especial de impuesto a la renta.
} 
una distribución estadística normal) en el caso de seguir evadiendo, a la microempresa no le conviene registrarse en el régimen laboral especial, porque el beneficio que este le ofrece es inferior o igual a los costos que le provoca. Si a esto se agrega la deuda tributaria de arrastre que podría cobrarse a la microempresa si se detecta que lleva varios años de establecida, no es extraño que el número de microempresas registradas en el régimen laboral especial haya sido tan bajo.

En la actualidad, las normas tributarias contemplan un régimen especial para unidades productivas pequeñas, que consiste en una simplificación de las obligaciones colaterales - exigencias de registros y libros de contabilidad - y de la forma de cálculo del impuesto a la renta (RER y RUS). Pero la situación real pareciera indicar que será indispensable un tratamiento más atractivo, al menos durante algún tiempo, si se desea que las 700.000 u 800.000 microempresas con potencial competitivo se registren para fines tributarios como parte de su proceso de formalización.

Parece indispensable entonces establecer un incentivo o crédito tributario para los que se formalicen con el fin de inducir a las microempresas a que se inscriban en los registros tributarios. La Superintendencia Nacional de Tributación (SUNAT) no pierde con esto, ya que hoy día no está percibiendo tributos de las microempresas evasoras.

\section{Aglomeraciones y subcontratación}

En la práctica, es difícil que con los recursos individuales de una microempresa se pueda financiar la capacitación

\section{$\mathrm{V}$}

\section{Conclusiones}

Más de la mitad de la población activa, ocupada en segmentos de muy baja productividad e ingresos (microempresas urbanas y rurales e independientes no calificados), no exhibió en 2002-2006 aumentos significativos de sus ingresos, pero sí pudo percibir cómo el resto de la población se beneficiaba con el auge económico. Este hecho, constatado en el presente análisis por segmentos del mercado laboral en dicho período, es uno de los factores que explican por qué una fracción significativa de los peruanos estuvo dispuesta en el 2006 a abandonar un modelo económico exitoso.

La economía peruana es esencialmente heterogénea. La heterogeneidad, provocada por profundas diferencias laboral y de gestión, las innovaciones, la mejora de la organización para la competitividad, el relevamiento de mercados, y temas similares. Por otro lado, es muy difícil implementar caso a caso una política selectiva a favor de las microempresas con potencial competitivo. Por consiguiente, tanto en interés de la microempresa como por razones de acceso a políticas públicas, un tema crucial es el de fomentar la asociatividad de hecho, es decir, impulsar las iniciativas de los microempresarios para agruparse en torno a necesidades concretas de sus empresas. Esto permitiría, por ejemplo, establecer servicios de asistencia técnica, capacitación laboral y capacitación en gestión para un conjunto de microempresas, lo que es mucho más viable y menos costoso que brindar los mismos servicios caso a caso. Lo mismo se puede aplicar al crédito con sistemas de garantías cruzadas.

Algo similar puede plantearse respecto a la entrada a mercados más exigentes, la subcontratación, la provisión de insumos para cadenas exportadoras, las compras estatales o incluso los consorcios de exportación. Para tener más posibilidades de éxito, las microempresas pueden conformar aglomeraciones (clusters) que les permitan aprovechar las economías de escala consiguientes.

Una manera de promover la asociatividad es procurar que los grupos, consorcios, asociaciones o colectivos de microempresas que se unan de hecho o de derecho tengan acceso preferente a las políticas propuestas más atrás, cuya incidencia sería entonces mayor. en el acceso a recursos, genera mercados segmentados de productos y factores. Los mercados laborales segmentados funcionan en la práctica en forma muy distinta a la que supone la teoría económica elaborada para mercados homogéneos. En ellos existen numerosos obstáculos, carencias y barreras que mediatizan la interacción de sus diversos segmentos. En ese contexto, la rápida expansión de los segmentos modernos y del empleo y los salarios en la pequeña, mediana y gran empresa formal no se traslada rápida y totalmente a los segmentos urbanos y rurales de la microempresa e independientes no calificados, porque: i) las tasas de incorporación de empleo a estos segmentos siguen siendo elevadas, lo que reduce el 
incremento de su ingreso laboral; y ii) las microempresas enfrentan carencias y barreras de acceso a recursos necesarios para expandirse competitivamente.

Una de las características de los mercados segmentados es que el proceso de ajuste de cada uno de sus segmentos y la velocidad de ese ajuste difieren de un segmento a otro. Una misma medida de política tiene efectos distintos que se hacen sentir con diferentes velocidades en cada uno de dichos segmentos.

La política económica en general está definida apuntando hacia los segmentos modernos y estructurados de un país. Es correcto que así sea, de otro modo el país no se desarrollaría. Pero, ¿qué sucede en realidades como la de Perú, en las que el grado de heterogeneidad y la segmentación de los mercados es sumamente elevada? ¿Qué sucede cuando $70 \%$ de la población depende de lo que ocurra en los mercados no estructurados? ¿Qué ocurre cuando el empleo en las empresas pequeñas, medianas y grandes es sólo el $17 \%$ del empleo total y el $53 \%$ de la ocupación total se halla en la microempresa urbana y rural? ¿Basta con promover el crecimiento del segmento de mayor productividad e ingresos? ¿Es suficiente en ese contexto plantear una política económica para los segmentos más modernos y estructurados y una política social para combatir la pobreza entre los que dependen del funcionamiento de los segmentos menos estructurados? Lo sucedido en Perú en los últimos 30 años tiende a confirmar que no es suficiente.

Y no lo es por la muy alta ponderación en el empleo de los segmentos de independientes no calificados y, muy especialmente, de los ocupados en microempresas. Por lo tanto, las políticas para elevar la productividad deben incluir aquellas que den a las microempresas con potencial competitivo un mayor acceso a los recursos necesarios. Desde este punto de vista, se hace indispensable establecer, entre otras políticas, un régimen laboral especial para las microempresas (normas laborales y, salario mínimo) y un régimen especial transitorio de tributación, e impulsar con más vigor políticas que mejoren el acceso de las microempresas al crédito, a los mercados, a la capacitación laboral y de gestión, a la innovación y que fomenten las diversas formas de agrupación de las microempresas. Estas políticas deberían apuntar a las aproximadamente 700.000 microempresas con potencial competitivo, y otorgar sus beneficios solo a aquellas que acepten "formalizarse". Como se planteó más atrás, los cambios institucionales —en las normas laborales y tributarias - complementan a las políticas que amplían el acceso a recursos. Por consiguiente, llevar a cabo los primeros sin las segundas no tiene la misma probabilidad de éxito que implementar ambos tipos de medidas simultáneamente.

La complementariedad e interdependencia entre las políticas enunciadas es otra razón que avala la conveniencia de desarrollar un conjunto de acciones de política a favor de la microempresa y no acciones aisladas. Así, por ejemplo, sin capacitación en gestión microempresarial y sin acceso a innovaciones el crecimiento de la productividad seguirá siendo muy lento y, por ende, persistirá la alta tasa de mortalidad entre las microempresas. Esto último afectará el acceso al crédito comercial. En consecuencia, lo más importante es poner en práctica un conjunto de políticas que elimine gradualmente, pero en forma simultánea, las principales restricciones.

Como criterio de política, todas las medidas expuestas deberán concentrarse en el desarrollo de los respectivos mercados - entre otros, de servicios de capacitación, de información y asistencia técnica para innovaciones y de servicios financieros - para ir logrando gradualmente que las microempresas con mayor potencial competitivo tengan mayores probabilidades de acceso a cada uno de esos mercados. Por esta vía, la intervención gubernamental puede ser mucho más exitosa que a través de la provisión estatal directa de esos servicios.

El verdadero desafío que encara la política económica en Perú es el de cómo concebir las medidas de políticas públicas de forma tal que generen el efecto buscado en los diferentes segmentos de los mercados sobre los que trata de incidir. Esto no significa que sea necesario concebir diferentes políticas económicas para diferentes segmentos. Se trata más bien de introducir en la política económica la idea de que sus efectos diferirán entre un segmento y otro, por lo cual las medidas que se adopten deberán incluir las necesarias para incidir selectivamente sobre los diferentes segmentos en la dirección deseada: por ejemplo, hacia la mejora de la competitividad. Esto nos aleja de la concepción habitual de una política económica para mercados homogéneos, y nos acerca a la realidad de Perú, una economía heterogénea con mercados segmentados. En otras palabras, nos aleja de la política económica de pizarra hecha para una imagen ideal, y nos obliga a pensar la política económica para el mundo real. 


\section{Bibliografía}

ADEX (Asociación de Exportadores) (varios años): MYPEs y exportaciones. Disponible en http://www.adexperu.org.pe.

Chacaltana, J. (2004): La capacitación laboral proporcionada por las empresas: el caso peruano, Lima, Centro de Estudios para el Desarrollo y la Participación (DEDEP).

División de Población (CELADE) (Centro Latinoamericano y Caribeño de Demografía (CElade) - División de Población de la CEPAL): Estimaciones y proyecciones de población. Disponible en http:// www.eclac.cl/celade/proyecciones

García, N. (2005): Competitividad y mercado laboral. Perú 1990-2004, serie Macroeconomía del desarrollo, $\mathrm{N}^{\circ}$ 41, LC/L.2440-P, Santiago de Chile, Comisión Económica para América Latina y el Caribe (CEPAL). Publicación de las Naciones Unidas, $N^{\circ}$ de venta: S.05.II.G.186.

(2007): Acceso a derechos laborales y recursos, borrador preliminar, Lima, Ministerio de Trabajo y Promoción del Empleo.

Matthews, J. (2007): MYPE competitiva, Lima, Agencia Andina de Noticias, marzo.

Ministerio de Economía y Finanzas (2006): Marco macroeconómico multianual 2007-09, Lima.

MTPE/PEEL (Ministerio de Trabajo y Promoción del Empleo/Programa de Estadísticas y Estudios Laborales) (2007): Base de datos del mercado laboral, Lima. 